\title{
Sobre "Un diálogo"
}

\author{
Juan Pablo Correa \\ Programa de Doctorat en Psicologia Social. Universitat Autònoma de Barcelona \\ jpablocorreas@hotmail.com
}

William James (1842-1910), el conocido psicólogo y filósofo estadounidense, es considerado una de las figuras intelectuales más importantes que ha producido la cultura de ese país, y uno de los principales autores de una corriente de pensamiento -el pragmatismo- que hoy identificamos como una de las mejores expresiones de esa misma cultura y, simultáneamente, uno de los principales aportes de los Estados Unidos de América a las posibilidades de autocomprensión con que cuenta en nuestros días la cultura occidental.

William James es hijo de William y Mary James, y hermano mayor de Henri James, el famoso novelista y dramaturgo. Su padre era teólogo y sus preocupaciones teológicas y espirituales ayudaron a configurar el pensamiento de su hijo William, quién dedicó una buena parte de sus reflexiones a intentar conciliar una comprensión naturalista darwiniana de la existencia humana con las creencias religiosas en las que fue socializado.

Junto a Charles Sanders Peirce (1839-1914) y John Dewey (1859-1952), William James es considerado uno de los fundadores del "pragmatismo americano", corriente de pensamiento en la que regularmente clasificamos también la obra de George Herbet Mead (1863-1931), el autor que más ha valorado la psicología social de entre todos ellos.

Antecedentes del pensamiento pragmatista en la historia del pensamiento $\mathrm{y}$, en particular, en la historia de la filosofía, hay muchos. Regularmente se mencionan como protopragmatistas, por ejemplo, Baruch Spinoza (1632-1677), David Hume (1711-1776), los nominalistas medievales y los sofistas de la antigua Grecia. También Friedrich Nietzsche (1844-1900) es considerado un antecedente importante del pensamiento pragmatista, no obstante su obra tuvo un desarrollo paralelo y casi contemporáneo al del pragmatismo americano. En nuestros días el pensamiento pragmatista ha vivido un renacimiento al ser reformulado explícitamente por filósofos tan importantes como Hillary Putnam, Jürgen Habermas y Richard Rorty.

Entre el primer pragmatismo y su formulación actual se encuentra la llamada filosofía analítica, corriente de pensamiento cuyo origen se vincula al trabajo de Bertrand Russell (1872-1970) y Ludwig Wittgenstein (1889-1951), y que encuentra su formulación más importante en los Estados Unidos en la obra de Willard V.O.Quine (1908-2000) y Donald Davidson. Es empleando los instrumentos que estos últimos autores construyeron, al realizar una crítica detallada de los postulados empiristas de la filosofía analítica, que Richard Rorty, Hillary Putnam y otros autores reelaboraron el pensamiento pragmatista estadounidense, con las herramientas que les ofrecía la filosofía contemporánea del lenguaje y tendiendo un puente entre las filosofías analítica y continental. ${ }^{1}$

${ }^{1}$ Un mapa muy interesante sobre este tema lo constituye el libro de Franca D’Agostini (1997) Analíticos y continentales. Guía de la filosofía de los últimos treinta años. Madrid: Cátedra, 2000. 
En todo caso la idea de un movimiento unitario llamado "pragmatismo" en la filosofía de fines del siglo XIX y comienzos del siglo XX, puede obedecer exclusivamente a "la necesidad chovinista de tener una filosofía americana". ${ }^{2}$ Esto se debe a que, si bien es cierto existía un fuerte vínculo e intercambio intelectual entre Peirce, James y Dewey, sus preocupaciones fundamentales y sus aportes a la filosofía y el pensamiento fueron también muy diferentes. Peirce es considerado uno de los padres de la semiología y un adelantado en lo que posteriormente se denominó el giro lingüístico de la filosofía, el que por lo general asociamos al nombre de Gottlob Frege (1848-1925). Los estudios de Peirce abarcaron un campo muy amplio de preocupaciones, las que incluyen desde las matemáticas, física y astronomía hasta la lógica, psicología y metafísica. Por su parte, John Dewey se interesó mucho más en temas ético-políticos y de educación que en cualquier otra cosa, pues su preocupación fundamental era la democratización de las relaciones sociales y el abandono progresivo de los componentes autoritarios de la cultura en que vivió, sustituyendo la autoridad por la fraternidad, en la cooperación comunitaria. Finalmente, William James realizó importantes aportes a la psicología y la filosofía, preocupándose de manera especial por encontrar la manera de conciliar ciencia y religión. En ese proceso James formuló su comprensión pragmatista de la verdad como lo que nos vendría mejor creer. En este sentido, James fue un utilitarista que conectó los ideales de eficacia y felicidad, considerando que su aporte a la realización futura de la felicidad humana es el único criterio que debemos adoptar a la hora de evaluar una creencia, ya sea en términos morales o epistemológicos.

Peirce tomó de Alexander Bain la definición de creencia como hábito de acción (Rorty, 2000) y la conectó con una comprensión antirrepresentacionalista de los procesos de indagación, afirmando que su función no es representar adecuadamente la realidad sino, más bien, ayudarnos a actuar eficazmente con ella. De este modo sustituyó representación por adaptación como orientación fundamental de los procesos de indagación, pues concebía el universo -y la historia humana dentro del mismo- como un proceso evolutivo. James admiraba a Peirce y compartía su punto de vista darwiniano antirrepresentacionalista, el que se pone de manifiesto en su teoría pragmatista de la verdad. Sin embargo la comprensión que Peirce tenía de la verdad como convergencia final de la indagación, no coincide con la definición que James nos da de la verdad como lo conveniente para nuestro modo de pensar. La concepción peirciana de verdad se ha proyectado en el pragmatismo contemporáneo a través de las concepciones de Putnam $^{3}$, Habermas ${ }^{4}$ y Apel, ${ }^{5}$ mientras que la de James ha inspirado la concepción de Rorty, quién ha empleado un conjunto de ideas proveniente de la obra de Donald Davidson para construir su formulación de la misma. ${ }^{6}$

El texto que incluimos en este número de Athenea es el último capítulo del libro de William James El significado de la verdad, ${ }^{7}$ publicado en inglés en 1909, dos años después de su obra Pragmatismo (1907), en la que expone con detalle su pensamiento filosófico. Lo más interesante de este texto probablemente sea la actualidad que muestran las ideas de James en el contexto de las discusiones de la filosofía contemporánea entre realistas y antirrealistas (dentro del pensamiento

${ }^{2}$ Richard Rorty (2000) El pragmatismo, una versión. Antiautoritarismo en epistemología y ética. Barcelona: Ariel, p.25

${ }^{3}$ Putnam, H. (1981) Razón, verdad e historia. Madrid: Tecnos, 1988.

${ }^{4}$ Habermas, J. (1999) Verdad y justificación. Madrid: Trotta, 2002.

${ }^{5}$ Apel, K.O. (1972-1973) La transformación de la filosofía. Madrid: Cátedra, 1996.

${ }^{6}$ Rorty, R. (1991) Objetividad, relativismo y verdad. Barcelona: Paidós, 1996.

7 James, W. (1909) El significado de la verdad. Madrid: Daniel Jorro, 1924. 
representacionalista) y entre representacionalistas y antirrepresentacionalistas, si incorporamos en la discusión las distinciones del pragmatismo rortyano (1991).

El dilema planteado por el interlocutor antipragmatista que James se inventa en este diálogo, supone la confrontación de tres concepciones distintas de "verdad". Por una parte la verdad como un estado o condición del mundo. Esto es, la verdad como una propiedad de la realidad o la verdad como un estado de cosas. Es lo que James llama "la mera existencia tal y cual de los hechos mismos". Por otra parte la verdad como un predicado de elogio para "algo conocido, pensado o dicho sobre la realidad", es decir, la verdad en el modo en que la conciben los pragmatistas. Por último la verdad como un "tercer estado", que se ubicaría entre la realidad (lo que conocemos o podemos conocer) y lo que conocemos, pensamos y/o decimos de ella. Es esta última idealización la que más interesa disolver a James por cuanto introduce una abstracción que media entre nuestro conocimiento de la realidad y la realidad misma, separándonos del mundo y orientando nuestras indagaciones en una dirección distinta a la mera descripción y/o explicación de entidades y relaciones entre entidades que forman parte del mundo. Se trata de una reformulación del mundo de las ideas de Platón o, lo que Rorty ha llamado "el espejo de la naturaleza", ${ }^{8}$ esto es, un mediador que hace las veces de un velo que cubre la realidad y la pone de principio fuera de nuestro alcance, de manera tal que conocer la realidad ya no es interactuar eficazmente con/en ella sino, más bien, coincidir con el espejo en el que esta se refleja.

La distinción entre realidad, verdad y conocimiento de la realidad que efectúa el antipragmatista del diálogo de James, corresponde a lo que posteriormente Donald Davidson llamó el tercer dogma del empirismo, ${ }^{9}$ esto es, una distinción entre esquema y contenido (del tipo forma / materia, apariencia / realidad, mapa / territorio, etc.). En este caso es la distinción entre verdad y realidad, por una parte, y entre conocimiento y verdad, por otra, lo que hace imposible conectar nuestros enunciados, conocimientos o pensamientos con aquello que enuncian, conocen o piensan. El problema de este tipo de distinciones, afirma Davidson, es que dan lugar al pensamiento relativista, pues hacen posible la duda sobre la validez de nuestras creencias en conjunto, en la medida que implican la posibilidad de que todo lo que conocemos pudiera no ser verdadero. Esta situación se produce por lo que James llama, al cerrar el diálogo, "el modo abstraccionista de pensar" y ha pasado a la filosofía y el pensamiento contemporáneos a través de innumerables formulaciones de la noción de "representación". ${ }^{10}$ El rechazo que el pragmatismo, en sus diversas versiones y etapas ha realizado de esta manera de concebir el proceso de conocimiento, no es sólo por razones epistémicas sino también por razones políticas. El posicionamiento antiautoritario de los pragmatistas apunta tanto a privatizar la religión, como propuso James, y con ello eliminar toda obligación de adecuar la organización de nuestras relaciones sociales a la voluntad de un padre colectivo (o un sustituto suyo), como a sustituir la adecuación a una Verdad eterna, un modo de ser del mundo o cualquier otra forma de poder no humano, por la construcción colectiva de un futuro mejor para todos, como metas de nuestra existencia colectiva (al modo en que lo formulara John Dewey).

\footnotetext{
${ }^{8}$ Rorty, R. (1979) La filosofía y el espejo de la naturaleza. Madrid: Cátedra, 1995.

${ }^{9}$ Davidson, D. (1992) Mente, mundo y acción. Barcelona: Paidós.

10 Una lectura al mismo tiempo semiótica y política del uso que se hace de esta noción en el pensamiento representacionalista es desarrollada por Bruno Latour (1987) en su libro La ciencia en acción. Barcelona: Labor, 1992. En este sentido "representar", además de "reflejar" o "sustituir" es también "hablar por" (el otro), esto es, lo que Tomás Ibáñez (1994) ha designado como una forma de ventriloquia disfrazada, en su libro Psicología social construccionista. México: Universidad de Gadalajara.
} 
Sin embargo, tal cual señala Rorty, William James se encontró con la dificultad de que su definición de "verdad" como aquello en lo que hemos de creer podía variar entre las distintas personas y grupos, lo que generaba la consecuencia contraintuitiva de que lo que es verdad para algunos podría no serlo para otros (y con ello introducía el pensamiento relativista). James no estuvo nunca seguro de cual de las estrategias para hablar de la verdad era la más adecuada, si entender -con Peirceque la verdad es lo que se creería en condiciones ideales o, más bien, seguir a Dewey en soslayar la cuestión de la verdad y hablar directamente de justificación en la conversación de una comunidad. La duda de James ha trascendido hasta el pragmatismo contemporáneo y hoy enfrenta, por un lado, el realismo interno de Putnam y la situación ideal de habla de Habermas (como reformulaciones contemporáneas de la posición de Peirce) y el uso precautorio de "verdad" que hace Rorty, como distinto de "justificación", al distinguir entre lo que una comunidad de justificación acepta hoy como verdadero (etnocéntricamente) y lo que otra comunidad, con mejores argumentos y/o más información, podría aceptar como tal el día de mañana.

\section{Un diálogo}

\section{William James}

Capítulo XV de

James, W. (1925). El significado de la verdad. Madrid: Daniel Jorro.

\section{UN DIÁLOGO}

Después de corregir pruebas de cuanto antecede, imagino que puede quedar en la mente del lector un estado residual de inconvencimiento, por lo que creo mi deber intentar, al menos, que desaparezca. Para ser más breve, expresaré mi pensamiento en forma de diálogo.

Antipragmático.-Decís que la verdad de una idea hállase constituida por su actuación. Pues bien, supongamos un cierto estado de hechos, por ejemplo, de la historia planetaria antediluviana, respecto a los cuales podría hacerse la siguiente pregunta: ¿Se podrá alguna vez conocer la verdad acerca de ellos? Y admitamos (dejando a un lado la hipótesis de un omnisciente absoluto) que la

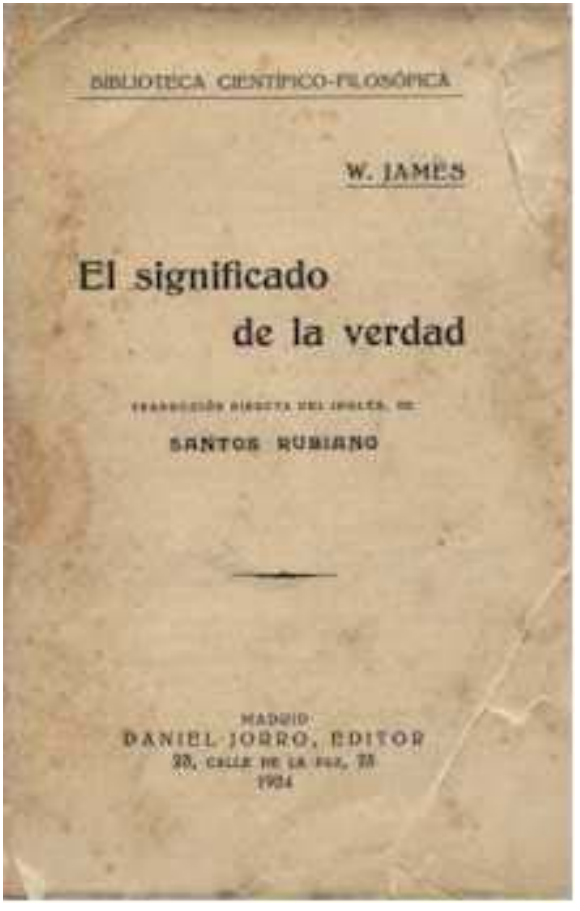

DANIEL jODRO, EDtTo:

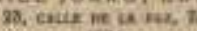


verdad no haya de ser conocida nunca. Yo os pregunto, hermano pragmatista, si, con arreglo a vuestra teoría, cabe decir que existe verdad alguna acerca de tal estado de hechos. ¿Existe o no verdad en los casos que en modo alguno pueden llegar a ser conocidos?

Pragmatista. - ¿Por qué me hacéis tal pregunta?

Antipragmático.- Porque pienso que os pone en un mal dilema.

Pragmatista._¿Por qué?

Antipragmático. -- Porque, si os inclináis a decir que existe tal verdad, rendís ipso facto toda la teoría pragmática, según la cual la verdad requiere ideas y actuaciones para constituirse; mas, en el presente caso, supónese no haber conocedor y, consiguientemente, no habría ni ideas ni actuaciones. ¿Qué os quedaría, pues, para hacer la verdad?

Pragmatista.-_Queréis, como muchos de mis adversarios, forzarme a construir la verdad de la realidad misma? No puedo; la verdad es algo conocido, pensado o dicho sobre la realidad, y, por consecuencia, adicionado a ella numéricamente. Acaso vuestro intento sea otra cosa; por lo cual, antes de decidirme por uno de los dos términos del dilema, yo os ruego me digáis qué puede dar de sí el otro término.

Antipragmático.-Pues que, si os inclináis a decir que no existiría verdad en las condiciones supuestas, porque no habría ideas ni actuación, iríais a dar de bruces en el sentido común. ¿No admite el sentido común que todo estado de hechos debe, en la naturaleza de las cosas, ser fielmente afirmable en alguna especie de proposición, aun cuando, en punto al hecho, la proposición no haya de ser establecida o propugnada por un alma viviente?

Pragmatista.-Indudablemente, eso es cierto, para el sentido común y para mí también. Son innumerables los hechos de la historia de nuestro planeta, de los cuales por nadie ni nunca se podrá dar una explicación, hechos de los cuales, empero, cabe decir abstractamente que siempre es posible una cierta explicación. La verdad acerca de tal hecho hállase, pues, genéricamente predeterminada por la naturaleza del hecho; por lo que podemos decir a toda conciencia que preexiste virtualmente. El sentido común tiene razón en su instintiva defensa.

Antipragmático,-_¿Es éste, pues, el término del dilema que admitís? ¿Decís, pues, que hay verdad, aun en casos en que no haya de ser conocida?

Pragmatista.- Ciertamente, bien que afirmándome en mi propio concepto de verdad; y no me digáis que haya de abandonarla por algo que no sé cómo entender. ¿No creéis también vosotros que existe una verdad aun en casos en que no deba ser conocida?

Antipragmático.-Claro que sí.

Pragmatista.- Decidme en qué, según vosotros, ha de consistir tal verdad respecto a lo desconocido.

Antipragmático.- ¿Consistir? ¿Qué entendéis por tal? Pues consiste en no otra cosa sino en ello mismo, o, con más propiedad, no tiene ni consistencia ni existencia; se fija, se obtiene. 
Pragmatista._- Perfectamente; ¿y en qué relación se halla con la realidad de la cual se obtiene?

Antipragmático._- ¿A qué se refiere usted al decir «por qué relación»? Claro es; la conoce, la representa.

Pragmatista. - ¿Quién la conoce? ¿Qué la representa?

Antipragmático.- La verdad, la verdad la conoce; o, más exactamente, la verdad es conocida por quienquiera que la posee. Toda verdadera idea de la realidad representa la verdad que la concierne.

Pragmatista.-Mas, yo creía que habíamos convenido en que no habría que suponer conocedor de ella, ni idea que la representara.

Antipragmático. —Ciertamente.

Pragmatista.-Pues entonces, decidme otra vez: ¿en qué consiste la verdad, por sí misma, ese tertium quid intermedio entre los hechos per se, de una parte, y de otra, todo conocimiento de ella actual o potencial? ¿Cuál sería su forma en este tercer estado? ¿De qué materia mental, física o epistemológica estará construida? ¿En qué reglón metafísica de la realidad habita?

Antipragmático.--Vaya unas preguntas más absurdas. ¿No es bastante decir que es verdad que los hechos son de tal y cual modo, y falso, que son de otro modo?

Pragmatista.- «Ello» es verdad que los hechos son tal cual, y me sustraigo a la tentación de preguntaros el qué de la verdad; pero sí quiero saber si la frase «es verdad que» los hechos son de tal y cual modo, significa realmente algo adicional a la mera existencia tal y cual de los hechos mismos.

Antipragmático. - Paréceme significar más que el mero ser de los hechos; una suerte de equivalente mental para ellos, su función epistemológica, su valor en términos poéticos.

Pragmatista.- Aparentemente una suerte de doble espiritual o su espíritu. De ser así, puedo preguntar a usted dónde se halla esta verdad.

Antipragmático.—¿Qué dónde? Pues no hay dónde: se obtiene simplemente, absolutamente.

Pragmatista.-Pero no en la mente de nadie.

Antipragmático.-No, porque hemos convenido que no cabría admitir conocedor actual de la verdad.

Pragmatista.- Convengo en que no haya conocedor actual. ¿Pero está usted cierto de que no haya noción de un conocedor potencial o ideal relacionado con la formación de tan extraña alusiva idea de verdad de los hechos de vuestra mente?

Antipragmático. - Claro que, de existir una verdad concerniente a los hechos, tal verdad es la que el conocedor ideal conocería. En tales límites no puede usted conservar separadamente la noción de aquélla y de él. Pero no es que sea primero él y luego siga ella; sino que, en mi opinión, es ésta la primera y luego le sigue él. 
Pragmatista. - Aun así quedo sumamente perplejo ante el status de la llamada verdad, suspendida como se halla entre cielo y tierra, entre la realidad y el conocimiento, fundada en la realidad, aunque numéricamente adicionada a ella y, al propio tiempo, antecedente a la aparición de todo conocedor y por completo independiente de ella. ¿Es tan independiente del conocedor como usted supone? Paréceme sumamente dudoso, como si ello pudiera ser solamente a modo de otro nombre para un potencial, distinto de un conocimiento actual de la realidad. Después de todo, ¿no es vuestra verdad, sencillamente, lo que cualquier afortunado conocedor tendría que conocer en caso de existir? Y en un universo donde no fueran ni concebibles los conocedores, ¿sería distinguible como existente verdad alguna sobre los hechos como algo numéricamente aparte? Tal verdad sería, a mi entender, inimaginable, inconcebible.

Antipragmático. - Creí haberos oído decir, poco ha, que hay una verdad de los hechos pasados, aunque sin nadie para conocerla.

Pragmatista.- Indudablemente; pero no debéis olvidar que yo también estipulé condiciones para definir la verdad a mi modo. La verdad de mi hecho pasado, presente o futuro es para mí solamente otro nombre para el hecho, si el hecho llega a ser conocido, hallándose predeterminada en cierto grado la naturaleza del conocimiento. La verdad que precede al conocimiento actual de un hecho, significa solamente lo que todo posible conocedor del hecho hallaráse a sí mismo necesitado de creer acerca de ella. Debe creer algo que le lleva a una relación satisfactoria con ella, algo que pueda ser un sustituto mental decente (decent). Lo que este algo pueda ser, claro es, fijase por la naturaleza del hecho y la esfera de sus asociaciones. /

Esto es todo lo que, a mi ver, cabe pensar claramente al decir que la verdad preexiste al conocimiento. Es conocimiento anticipado, conocimiento en forma de mera posibilidad.

Antipragmático. - ¿Pero qué es lo que el conocimiento conoce cuando llega? ¿No conoce la verdad? $\mathrm{Y}$, de ser así, ¿no sería la verdad distinta, tanto del hecho como del conocimiento?

Pragmatista.-Paréceme que lo que el conocimiento conoce (knowledge knows) es el hecho mismo, el suceso o lo que fuere la realidad. Donde ustedes ven tres realidades distintas, la realidad, el conocedor y la verdad, yo veo sólo dos. Además, yo puedo ver lo que de mis dos entidades es conocido como; mas al preguntarme a mí mismo cuándo es conocida-corno la verdad en vuestra tercera entidad, por una parte, no topo con nada distinto de la realidad, y, por otra, hallo las vías por donde pueda ser conocida.

¿No estaréis mal orientados por el lenguaje corriente, que ha hallado muy cómodo introducir un nombre híbrido, significativo algunas veces de un género de conocer y otras de una realidad conocida, aplicándolo de modo alternativo e intercambiable a una u otra de estas cosas? ¿Va ganando algo la Filosofía con perpetuar y consagrar tal ambigüedad? Si denomináis realidad al objeto de conocimiento y verdad al modo en que es conocido (conocido además en particulares ocasiones y variamente por seres humanos que individualmente tienen con ellos relaciones varias), y si mantenéis firmemente tal nomenclatura, creo que así eludís toda suerte de tropiezo.

Antipragmático. - ¿Decís, pues, que creéis haber podido eludir mi dilema?

Pragmatista.- Ciertamente; porque si verdad y conocimiento son términos correlativos e ínterdependientes, según he mantenido, donde quiera que sea concebible el conocimiento será 
concebible la verdad; donde quiera que la verdad sea posible, será posible la verdad; donde quiera que el conocimiento sea actual lo será la verdad. Por lo tanto, acerca de la primera premisa creo que la verdad es actual y digo que no existe; no existe puesto que, por hipótesis, no hay conocedor, ideas ni actuación. Convengo, sin embargo, que puede existir la verdad posible o virtual, porque puede posiblemente originar un conocedor; y la verdad concebible existe ciertamente, porque, considerada en abstracto, nada hay en la naturaleza de los hechos antediluvianos que haya de hacer inconcebible la aplicación a ellos. del conocimiento. Por lo tanto, cuando se trata de empalarme en la segunda premisa, tengo a la verdad en cuestión como posibilidad meramente abstracta, y así digo que existe, de par con el sentido común.

Estas distinciones ¿no me libran justamente de todo embarazo y no creéis que os sirvan también a vosotros?

Antipragmático._- ijamás! Eso es un puro sofisma. La verdad no es sino la verdad, y nunca debe ser degradada identificándola con bajos particulares pragmáticos al modo que proponéis.

Pragmatista.-Bien, querido adversario; no esperaba convencer a un tan eminente intelectualista y lógico como usted; goce usted mientras viva de su inefable concepción. Quizá la próxima generación pueda acostumbrarse más a la interpretación concreta y empírica de los términos en que consiste el método pragmático y quizá se maraville de que una explicación de la verdad como la mía haya topado con dificultades para penetrar en entendimientos de hombres inteligentes sin par, bien que torcidos por educación y tradición hacia el modo abstraccionista de pensar. 